\begin{tabular}{|c|c|c|}
\hline $\begin{array}{l}\text { ISSN 2525-4812 (versão online) } \\
\text { ISSN 2238-7641 (versão impressa) } \\
\text { http://www.revistaterceiramargem.com/ } \\
\text { index.php/terceiramargem/index }\end{array}$ & $\begin{array}{c}\text { Recebido em: 19/6/2019 } \\
\text { Aprovado em: 30/2/2020 } \\
\text { Período de publicação: jul/dez, } 2020\end{array}$ & $\begin{array}{c}\text { Revista Terceira } \\
\text { Margem Amazônia } \\
(\text { v. } 6 \cdot \mathrm{n} .15 \cdot \mathrm{Jul} / \mathrm{Dez} 2020)\end{array}$ \\
\hline
\end{tabular}

Como citar o artigo:

ERAZO, R. L; COSTA, S. C. F. das C; SILVA, L. J. S. A importância da mulher na agricultura familiar: Comunidade Lago Janauacá, Careiro Castanho - AM. Revista Terceira Margem Amazônia, v. 6, n.15, p. 242-255, 2020. Doi: http://dx.doi.org/10.36882/2525-4812.2020v6i15p242-255.

\title{
A IMPORTÂNCIA DA MULHER NA AGRICULTURA FAMILIAR: COMUNIDADE LAGO JANAUACÁ, CAREIRO CASTANHO - AM
}

\author{
Rafael de Lima Erazo ${ }^{1}$ \\ Sarah Caroline Ferreira das Chagas Costa ${ }^{2}$ \\ Lindomar de Jesus de Sousa Silva ${ }^{3}$
}

Resumo: A Amazônia é, seguramente, uma região onde a agricultura familiar se manifesta das mais diferentes formas: ribeirinha, extrativista, quilombolas, dentre outros, e onde se encontra uma grande diversidade de recursos naturais capazes de prover a base produtiva e alimentar desses agricultores. O aumento do interesse pelas discussões sobre a importância social e econômica dessa unidade produtiva se materializou em políticas públicas, como o Programa Nacional de Fortalecimento da Agricultura Familiar (PRONAF), além do revigoramento da Reforma Agrária, destinadas a promover a melhoria da condição de vida deste segmento. A importância desse estudo assenta-se na necessidade de melhor conhecer a realidade da mulher na agricultura familiar no contexto amazônico e a sua importância para a sociedade contemporânea. É necessário que haja uma melhor compreensão da dinâmica interna das explorações familiares e do grau de sua integração ao sistema econômico e social vigente, através da análise da situação atual da Comunidade Lago Janauacá, promovendo uma discussão sobre a real igualdade entre os gêneros. O Objetivo desse trabalho é apresentar uma discussão a respeito do papel da mulher na agricultura familiar da região Amazônica. Os objetos que compuseram o universo da pesquisa foram as unidades familiares de produção associadas aos circuitos de produção e comercialização das "casas de farinha" flutuantes da região do lago Janauacá, município de Careiro, no Estado do Amazonas. Com esse estudo, pode-se verificar que na Amazônia, a mulher tem apresentado crescimento expressivo das atividades no campo. Porém, esse estudo ainda mostrou o retrato brasileiro da escolaridade da mulher que sobrevive do trabalho no campo. São necessárias políticas públicas que garantam o acesso à terra para a mulher, que proporcionem educação, cultura e lazer, que auxiliem na geração de emprego e na melhoria da renda das famílias que

\footnotetext{
${ }^{1}$ Engenheiro agrônomo, doutorando em ciências do ambiente e sustentabilidade na Amazônia (UFAM), rafael_erazo2000@yahoo.com.br

${ }^{2}$ Engenheira de alimentos, especialista em microbiologia, Professora substituta do curso de Engenharia de alimentos (UFAM), sarah23caroline@gmail.com

${ }^{3}$ Sociólogo, doutor em desenvolvimento sustentável (UFPA), Pesquisador da Embrapa Amazônia Ocidental.
} 
vivem da agricultura familiar no Amazonas. E principalmente, a valorização e a quantificação do trabalho das mulheres tenham reconhecimento, pois este contribui de maneira significativa para a sobrevivência e para a reprodução da família.

Palavras-chaves: Amazônia, Ruralidade, Sustentabilidade.

\begin{abstract}
The Amazon is certainly a region where family farming manifests itself in many different ways: riverside, extractive, quilombolas, among others, and where there is a great diversity of natural resources capable of providing the productive and food base for these farmers. The increase in interest in discussions about the social and economic importance of this productive unit materialized in public policies, such as the National Program for Strengthening Family Agriculture (PRONAF), in addition to the reinvigoration of Agrarian Reform, aimed at promoting the improvement of living conditions. this segment. The importance of this study is based on the need to better understand the reality of women in family farming in the Amazon context and its importance for contemporary society. It is necessary to have a better understanding of the internal dynamics of family farms and the degree of their integration into the current economic and social system, through the analysis of the current situation of the Lago Janauacá Community, promoting a discussion about the real equality between genders. The objective of this work is to present a discussion about the role of women in family farming in the Amazon region. The objects that made up the research universe were the family production units associated with the production and marketing circuits of the floating "flour houses" in the region of Lake Janauacá, municipality of Careiro, in the State of Amazonas. With this study, it can be seen that in the Amazon, women have shown significant growth in activities in the field. However, this study still showed the Brazilian portrait of the education of women who survive from working in the field. Public policies are needed to guarantee access to land for women, to provide education, culture and leisure, to help generate jobs and improve the income of families living on family farming in Amazonas. And especially, the valorization and quantification of women's work is recognized, as it contributes significantly to the survival and reproduction of the family.
\end{abstract}

Keywords: Amazon, Rurality, Sustainability.

\title{
INTRODUÇÃO
}

A Amazônia é, seguramente, uma região onde a agricultura familiar se manifesta das mais diferentes formas: ribeirinha, extrativista, quilombolas, dentre outros, e onde se encontra uma grande diversidade de recursos naturais capazes de prover a base produtiva e alimentar desses agricultores (GALVÃO et al., 2005).

O estudo dos sistemas de produção possibilita compreender as dinâmicas sociais, econômicas, ambientais, culturais e políticas dos agricultores familiares em sua relação 
ERAZO, R. de L.; COSTA, S. C. F. das C.; SILVA, L. de J. de S.

com a complexidade e diversidade do ambiente, integração ao mercado e políticas públicas (MATOS e MARIN, 2009). Segundo Guanziroli et al. (2001), a diversidade de situações, nas quais se encontra a agricultura familiar, reflete-se nos diferentes sistemas de produção adotados, que podem ter efeitos diferenciados, em diferentes regiões.

Schneider (2003), ao analisar o debate brasileiro sobre a agricultura familiar, afirma que a emergência da expressão agricultura familiar na literatura brasileira ocorre no início da década de 1990, quase simultaneamente, em duas esferas distintas. De um lado, no campo político, a adoção da expressão parece estar relacionada aos embates que os movimentos sociais tiveram nas discussões acerca do espaço e o papel dos pequenos produtores rurais, de outro, por intermédio de alguns trabalhos acadêmicos que passaram a buscar novos referenciais teóricos e analíticos, no referido período, e que contribuiu para introduzir a expressão agricultura familiar.

O aumento do interesse pelas discussões sobre a importância social e econômica dessa unidade produtiva se materializou em políticas públicas, como o Programa Nacional de Fortalecimento da Agricultura Familiar (PRONAF), além do revigoramento da Reforma Agrária, destinadas a promover a melhoria da condição de vida deste segmento. Sendo que, a formulação das políticas favoráveis à agricultura familiar e à Reforma Agrária obedeceu, em boa medida, às reivindicações de trabalhadores rurais e à pressão dos movimentos sociais organizados. No entanto, não se pode afirmar que a agricultura familiar tem sido reconhecida como prioridade pelos governos, este segmento ainda enfrenta muitos problemas, como os altos preços dos insumos agrícolas, a demanda irregular do mercado e os baixos preços de mercado para seus produtos (MESQUITA; MENDES, 2012)

A agricultura familiar, compreendida como uma forma de produção agrária em menor escala, com alternativas de trabalho mais manuais e artesanais, utilização de mão de obra basicamente familiar ou de grupos de convívio da vizinhança e amigos, tem sido fonte de produção e movimentação de capital social (GONÇALVES; VITAL, 2014). Em decorrência disso, movimenta implicações na elaboração de políticas públicas para a sua garantia e manutenção (GONÇALVES; VITAL, 2014; SALVARO, LAGO; WOLF, 2013). Primeiramente, deve-se esclarecer que a agricultura familiar é, conforme os autores, um cenário no qual o trabalho se dá basicamente através da força familiar e comunitária. A partir disso, a discussão a respeito dos papéis de gênero e suas devidas ocupações vem sendo tema de diversas publicações a respeito desse panorama (LASSAK, 2010; NOGUEIRA et. al., 2016; PINTO et. al., 2013). 
ERAZO, R. de L.; COSTA, S. C. F. das C.; SILVA, L. de J. de S.

Para Marion e Bona (2013), no surgimento da agricultura familiar vemos a mulher assumir um papel cada vez mais relevante, tendo em vista a introdução da mecanização e tecnologias que facilitam as atividades quanto à necessidade de força bruta, proporcionando maior espaço de atuação às mulheres agricultoras. Mesmo assim, a situação está longe do ideal, ora por preconceito da unidade familiar, ora por falta de incentivo e capacitação. Sua dedicação e contribuição para com este regime vem aumentando gradativamente, uma vez que este modelo de produção não se utiliza da mão de obra contratada, limitando suas atribuições aos membros da família.

\section{PROBLEMA DE PESQUISA E OBJETIVOS}

Segundo Mesquita (2013), os movimentos femininos e feministas incorporaram uma nova perspectiva pautada pela noção de gênero, e começaram a resgatar e/ou construir a cidadania da mulher trabalhadora rural, proporcionando uma maior visibilidade às agricultoras. A 'invisibilidade' do papel das mulheres na agricultura familiar está associada à divisão sexual e social do trabalho, na qual as mulheres são responsáveis pelo trabalho reprodutivo e os homens pelo trabalho produtivo. Esta questão contribui para a gratuidade, e consequentemente, para a 'invisibilidade' do seu trabalho, uma vez que, o trabalho dito reprodutivo não tem caráter mercantil e o seu trabalho ligado à produção é reduzido a uma ajuda. É importante salientar que a cultura patriarcal, inserida tanto no modo de pensar dos homens como das mulheres, principalmente, no meio rural, contribui para a visão de que o lugar do trabalho da mulher é na esfera doméstica, voltado aos cuidados com a família e a casa.

Nas unidades produtivas familiares que praticam a pluriatividade as mulheres atuam como atores centrais, combinando atividades tanto agrícolas como não agrícolas, pois esta associação advém da necessidade de diversificação das fontes de renda familiar (RÖHNELT, 2010). Contudo percebemos que poucas são as atribuições e a quantidade de mulheres que fazem essa diversificação por entender que ainda existe o preconceito da capacidade de fazer atividades que são dominadas pela classe masculina como por exemplo: operar máquinas agrícolas, atuarem como titulares de financiamentos para investimentos, ser vista como sucessoras nas atividades da propriedade que hoje nas famílias é preparado o(s) filho(s) e não a(s) filha(s) (MARION; BONA, 2013).

As mulheres agricultoras não são apenas as principais responsáveis pelas atividades de manutenção do núcleo familiar, mas desempenham um papel fundamental 
ERAZO, R. de L.; COSTA, S. C. F. das C.; SILVA, L. de J. de S.

no trabalho relacionado a lavouras e a criação de animais. Sendo assim, elas possuem uma grande importância na dinâmica da unidade de produção, interferindo diretamente nas diferentes esferas de atuação produtiva e reprodutiva (MESQUITA; MENDES, 2012).

Diante dessas considerações, a importância desse estudo assenta-se na necessidade de melhor conhecer a realidade da mulher na agricultura familiar no contexto amazônico e a sua importância para a sociedade contemporânea, pois, é necessário que haja uma melhor compreensão da dinâmica interna das explorações familiares e do grau de sua integração ao sistema econômico e social vigente, através da análise da situação atual da Comunidade Lago Janauacá, promovendo uma discussão sobre a real igualdade entre os gêneros.

\section{FUNDAMENTAÇÃO TEÓRICA}

No que se refere ao papel político das mulheres na ruralidade, foi somente a partir de agosto de 1994, com o lançamento da cartilha "Nenhuma trabalhadora rural sem documentos", que trazia informações sobre a garantia de seus direitos civis perante o Estado, que o trabalho das mulheres agricultoras foi visto e validado em seus direitos (SALVARO et al., 2013).

Entretanto, apesar desse marco, o trabalho dessas mulheres ainda é desvalidado, pois são elas que asseguram o bem-estar da família e a reprodução social, e apesar da extensa jornada de trabalho, que implica cuidar da casa e ajudar os cônjuges na lavoura, ainda é um trabalho não reconhecido financeiramente, o que implica no aumento da desigualdade financeira (COSTA et. al., 2014). A partir do momento em que surgem políticas públicas que impulsionam um movimento de autorreflexão sobre o papel esperado, como no caso da cartilha, essas mulheres passam a ter a oportunidade de vivenciar uma tensão saudável para a reorientação de sentido (FRANKL, 2008).

Ainda sobre a renda dessas mulheres, os dados do censo de 2010 do IBGE apontam que na região rural sul o rendimento das mulheres em relação ao total familiar é de apenas 37,3\%. Esse índice corrobora para a afirmação das relações de trabalho desiguais, sendo o poder financeiro ou de compra destinado aos homens, fortalecendo a não formalização do trabalho dessas mulheres, bem como a dependência do modelo patriarcal para obtenção de renda (MAIA; SANT’ANA, 2011, PINTO et. al., 2013). 
ERAZO, R. de L.; COSTA, S. C. F. das C.; SILVA, L. de J. de S.

A ironia desses achados traz a reflexão sobre um modelo predominante sexista, que impulsionou nos anos 1970 a necessidade das vertentes feministas que lutavam pelo reconhecimento das mulheres e igualdade no mercado de trabalho (PILAR, 2013). Essas mulheres, além de trabalharem no meio rural no auxílio de renda familiar, enfrentam a dura "jornada dupla", pois dedicam em média o dobro do tempo que os homens nos afazeres domésticos e reconhecem seu trabalho rural apenas como uma ajuda a seus companheiros (PINTO et. al., 2013).

Conforme Maia e Sant'ana (2011), os papéis de gênero no meio rural são evidenciados desde a adolescência. Observa-se uma questão notável referente à diferenciação dos papéis de gênero desde essa fase vital: os meninos têm a possibilidade de atingir maior escolaridade e a expectativa de ficarem como herdeiros das propriedades, enquanto as mulheres permanecem no papel de cuidadoras. Além disso, amparados pela religião, a delimitação desses papéis se torna clara: as mulheres são vistas como procriadoras destinadas aos afazeres domésticos e ao cuidado dos filhos e do marido, e os homens trabalham na roça, tidos como provedores do sustento da casa (LASSAK, 2010; PINTO et. al., 2013; NOGUEIRA et. al., 2016). Assim, espera-se que as atividades permaneçam e se perpetuem dentro da história familiar nesse cenário rural.

\section{METODOLOGIA}

\section{Local estudado}

Os objetos que compuseram o universo da pesquisa foram as unidades familiares de produção associadas aos circuitos de produção e comercialização das "casas de farinha" flutuantes da região do lago Janauacá, município de Careiro, no Estado do Amazonas (Figura 1). 
ERAZO, $R$. de L.; COSTA, S. C. F. das C.; SILVA, L. de J. de S.

Figura 1: Lago Janauacá, Careiro Castanho (AM).

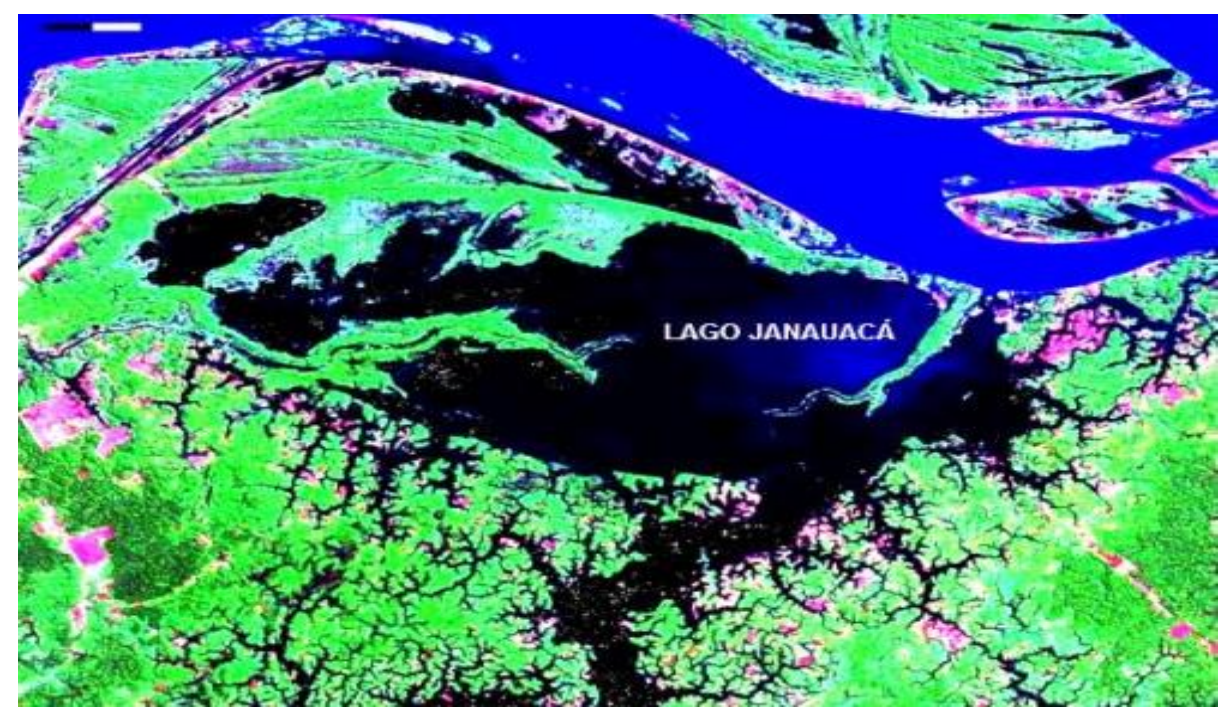

Fonte: INPE (2012)

\section{Tipo da pesquisa}

Para atingir os objetivos propostos neste estudo, propusemos uma pesquisa de cunho exploratório, descritivo e explicativo com viés qualitativo e quantitativo, obtida através de entrevistas estruturadas aplicadas aos agricultores das unidades de produção familiar. Para a obtenção de dados primários sobre a participação da mulher na agricultura amazônica, foram realizadas coletas de dados que ocorreram durante o mês de agosto de 2016, com a amostra composta por 79 entrevistas nesse estudo.

$\mathrm{Na}$ pesquisa, foram utilizadas as seguintes técnicas de pesquisa para a coleta de dados: teste piloto, observação simples e entrevistas.

- Realização de teste piloto: Foi realizado junto aos agricultores familiares na área da pesquisa. O objetivo desta etapa foi de testar os instrumentos de levantamento de dados, identificando e corrigindo suas limitações e imperfeições para melhor atender aos objetivos da pesquisa.

Para auxiliar no registro das observações foram utilizados os seguintes materiais: gravador de voz - foi utilizado para registrar os discursos das agricultoras; câmera fotográfica - utilizada para registrar as imagens no levantamento de dados. Foram também utilizadas anotações das observações sobre o cotidiano das mulheres.

Foi também utilizada a entrevista estruturada, pois esta modalidade enfoca um tema bem específico, permitindo ao entrevistado falar livremente sobre o assunto, mas quando este se desvia do tema principal, o entrevistador esforça-se para a sua retomada. 
ERAZO, R. de L.; COSTA, S. C. F. das C.; SILVA, L. de J. de S.

\section{RESULTADOS E DISCUSSÃO}

Na região estudada, observou-se a existência de uma leve predominância de homens "chefiando" as unidades de produção em terra firme no Janauacá: 59,2\% são homens e 40,8\% são mulheres (Figura 2). Porém, houve também uma participação expressiva de mulheres que se declararam chefes de família, o que faz refletir também sobre a participação destas no trabalho e no auxílio à manutenção de suas famílias.

Figura 2: Gênero dos agricultores na Comunidade Lago no Janauacá.

\section{Gênero dos agricultores}

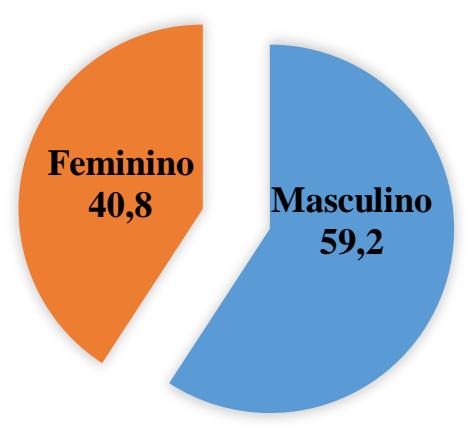

Para Costa (2009), esta situação decorre da baixa oferta de emprego para indivíduos com baixa escolaridade nas áreas urbanas, o que direciona ou mesmo mantém grande parte no meio rural, onde o homem, pela sua condição corpórea (física), se torna mais produtivo e, com isso, assume as despesas da casa, bem como a chefia da família, conformando o processo de "masculinização" do meio rural. O autor considera, ainda, que as mulheres apresentam tendência maior para buscar os estudos e a qualificação profissional e, deste modo, abandonam o meio rural ou mesmo assumem a chefia da família, por serem melhores remuneradas, em função da sua melhor capacitação profissional.

$\mathrm{Na}$ agricultura familiar a busca pela autonomia das mulheres não é diferente do que o mercado de trabalho formal, cada vez mais as mulheres participam e representam parcela importante na participação da renda familiar, segundo Ministério do Trabalho e Emprego, a participação das mulheres no mercado de trabalho cresceu mais do que a dos 
ERAZO, $R$. de L.; COSTA, S. C. F. das C.; SILVA, L. de J. de S.

homens em 2012. O crescimento foi de 3,89\%, com isso, as mulheres passaram a representar 42,47\% da força de trabalho. (SOUZA; PLEIN, 2015).

Ainda de acordo com Souza e Plein (2015), as mulheres têm capacidade também de gestionar seus recursos, procuram fazer ações cautelosas que tragam rentabilidade e segurança para as finanças da família. Mulheres cuidam mais do dinheiro, fazem das pequenas economias as grandes conquistas que a família busca. Procuram cuidar do bemestar, ter na casa o máximo de conforto, cuidam da educação dos filhos. É uma forma diferente de olhar o dinheiro, observando de uma forma mais social, que considera as diversas variáveis que vai além do fator de se ter uma quantia em reais e sim de garantir os benefícios ao grupo familiar e meio onde vivem.

Assim pode-se inferir que a mulher é importante para a vida da família no meio rural, pois, além do trabalho do lar, contribui no complemento da renda familiar. A valorização do trabalho feminino no meio rural também é uma forma de garantir o desenvolvimento da agricultura familiar. Existe a necessidade de um conjunto de mudanças sociais e políticas que visem à igualdade, à solidariedade e a inclusão social, assim como, as mudanças nas relações de gênero.

Tedesco (1999), afirma que o trabalho da mulher é visto além de auxiliar para o bem-estar da família; é expressivo do esforço que fazem para encontrar formas de gerar rendas adicionais no núcleo familiar; aumentando, sem dúvida, sua carga de trabalho, complexificando seu vínculo com o espaço doméstico.

A figura 3, mostra que as mulheres agricultoras são alfabetizadas, pois, a maior parte delas apresentam a escolaridade entre $2^{\mathrm{a}}$ e $5^{\text {a }}$ série primária, hoje Ensino Fundamental I. Mostrando, que as agricultoras ainda veem o casamento como alternativa na vida no meio rural, diferentemente dos homens, que sempre priorizam o trabalho rural.

Figura 3: Escolaridade das mulheres na Comunidade Lago no Janauacá. 
ERAZO, R. de L.; COSTA, S. C. F. das C.; SILVA, L. de J. de S.

\section{Escolaridade das Mulheres da comunidade do Lago do Janauacá}

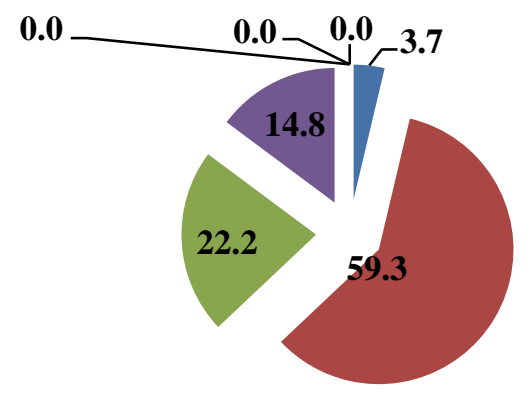

$$
\begin{aligned}
& \square 1^{\circ} \\
& \square 2^{\circ} \text { a } 5^{\circ} \\
& 6^{\circ} \text { a } 8^{\circ} \\
& \square \text { Ens. Méd. Inc. } \\
& \square \text { Ens. Méd. Com. } \\
& \square \text { Ens. Sup. Inc. } \\
& \square \text { Ens. Sup. Com. }
\end{aligned}
$$

Observou-se baixa formação educacional para grande parte das entrevistadas, quadro que, segundo Castro (2009), expressa uma realidade muito presente no contexto das populações rurais de várias regiões do país, sobretudo das regiões norte e nordeste. Esta característica reflete certo nível de abandono, ao qual as populações rurais estão sujeitas, uma vez que, devido à distância, as instituições de ensino não chegam até as populações rurais e, nessa condição, ou se estuda pouco ou até não se estuda, pelos empecilhos encontrados no acesso à educação (FREITAS, 2011).

Batliwala (1994) afirma, acertadamente, que o reconhecimento da mulher na agricultura familiar é um processo e, com certeza, este processo não é linear. Pode-se constatar que o processo desse empoderamento tende a ser espiral. Algumas das mulheres não se empoderaram, de fato, ou melhor, o grau de seu empoderamento foi baixo em relação a outras e ao que poderia ser. Em alguns casos, isto se deveu à pouca escolaridade, à idade e ao ambiente que as circunda. Os agentes facilitadores, em geral, não favoreceram o entendimento crítico destas mulheres sobre sua realidade, autonomia e capacidade de fazerem suas próprias escolhas.

Segundo Chayanov (1974), o que determinará a realização de atividades não agrícolas será o tamanho da família, o período climático da região, a falta de meios de produção e a situação dos mercados, favorecendo melhores rendimentos. A divisão do trabalho na unidade familiar entre atividades agrícolas e não agrícolas se dará de acordo com o equilíbrio entre produção e consumo. Quando a família não dispõe de meios suficientes para produzir ou quando há força de trabalho disponível, o agricultor busca em atividades não agrícolas uma forma de ocupação para garantir o equilíbrio entre trabalho (produção) e consumo. 
ERAZO, R. de L.; COSTA, S. C. F. das C.; SILVA, L. de J. de S.

Assim com esses fatores citados, muitas vezes as agricultoras dessa localidade buscam alternativas para garantir a estabilidade da família como a procura por parte dessas mulheres por ocupação fora da propriedade de produção (Figura 4).

Figura 4: Razões citadas pelas agricultoras para o trabalho fora da propriedade

\section{Principal razão das moradoras da comunidade Lago do Janauacá para o trabalho fora da propriedade}

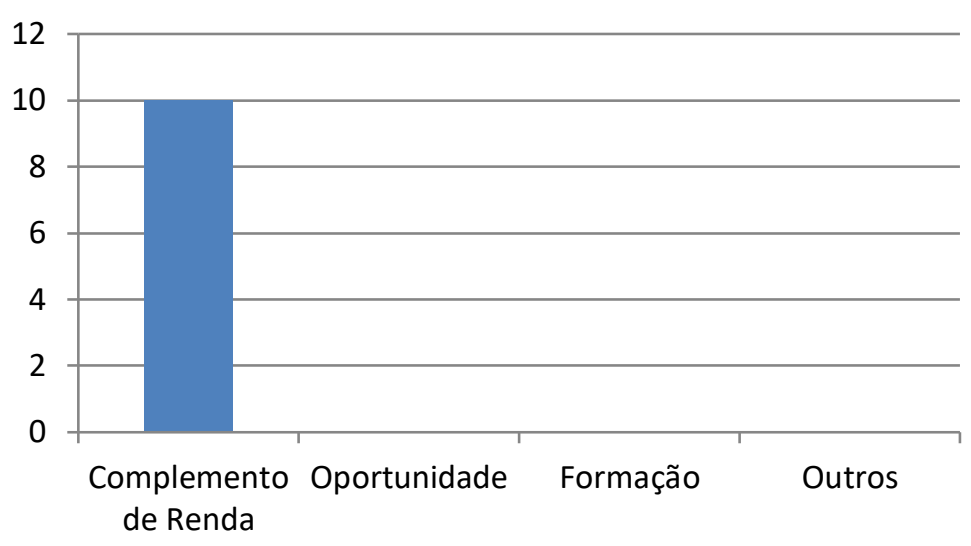

Quando a unidade camponesa consegue a sua sustentabilidade através da produção de farinha, os seus componentes se ocupam exclusivamente disso. Nesse caso, retira-se a proporção da farinha para o consumo da família e comercializa-se o excedente para adquirir os outros produtos necessários para a sobrevivência de todos os seus membros. Quando a produção da farinha não permite isso, faz-se o uso do trabalho acessório (OLIVEIRA, 2007).

Para Mesquita e Mendes (2012), a importância de dar visibilidade ao trabalho da mulher, não somente na agricultura familiar, mas em todos os campos de trabalho. Para que isso de fato ocorra, é necessário o desenvolvimento de políticas públicas mais eficazes que proporcionem às mulheres os mesmos direitos que aos homens e adotar medidas que as incentive e as esclareceram na utilização dos seus direitos. Assim, elas poderão conquistar uma participação mais respeitada dentro da agricultura familiar, bem como autonomia para atuarem tanto na produção quanto na administração da sua família. Isso contribuirá para valorização da agricultura familiar e para transformar as relações sociais de gênero. 
ERAZO, $R$. de L.; COSTA, S. C. F. das C.; SILVA, L. de J. de S.

\section{CONSIDERAÇÕES FINAIS}

A mulher na agricultura familiar estava relacionada ao matrimônio e à reprodução, sendo vistas como procriadoras destinadas aos afazeres domésticos e ao cuidado dos filhos e do marido. Porém investigações atuais mostram a mudança desse panorama. A importância de se olhar a mulher como fator fundamental na pequena produção, está relacionada ao fato de que, se as condições entre homens e mulheres do campo fossem igualitárias, a produção agrícola dos países teria acréscimo nas suas produções.

Com esse estudo, pode-se verificar que na agricultura familiar amazônica, a mulher também tem apresentado um crescimento expressivo. Porém, ainda mostrou um retrato brasileiro da escolaridade da mulher que sobrevive do trabalho no campo. A problemática inicia-se nas relações de gênero e perpassa o cerne do processo produtivo.

Perante essas informações, são necessárias políticas públicas que garantam o acesso à terra para a mulher, que proporcionem educação, cultura e lazer, que auxiliem na geração de emprego e na melhoria da renda das famílias que vivem da agricultura familiar no Amazonas. E principalmente, a valorização e a quantificação do trabalho das mulheres tenham reconhecimento, pois este contribui de maneira significativa para a sobrevivência e para a reprodução da família.

\section{REFERÊNCIAS}

BRASIL. INSTITUTO BRASILEIRO DE GEOGRAFIA E ESTATÍSTICA- IBGE. Estimativas (2010). São Paulo: IBGE.

BATLIWALA, Srilatha. The meaning of women's empowerment: new concepts from action. In: SEN, Gita; GERMAIN, Adrienne; CHEN, Lincoln C. (Ed.). Population policies reconsidered: health, empowerment and rights. Boston: Harvard University Press, 1994. p. 127-138.

CASTRO, J. A. Evolução e desigualdade na educação brasileira. Educ. Soc., Campinas. 2009; 30 (108): 673-697.

CHAYANOV, A. V. La organización de la unidad económica campesina. Buenos Aires, Ediciones Nueva Visión, 1974. (Primeira edição, Moscou, 1925).

COSTA, M. G. S. G., DIMENSTEIN, M. D. B., LEITE, J. F. (2014). Condições de vida, gênero e saúde mental entre trabalhadoras rurais assentadas. Estud. psicol. (Natal), 19 (2), 145-154. doi: 10.1590/S1413-294X2014000200007.

FRANKL, V. E. (2008). Em busca de sentido. Petrópolis: Vozes. 
FREITAS, C. G. de; FARIAS, C. S. de; VILPOUX, O. F. A produção camponesa de farinha de mandioca na Amazônia sul ocidental. Bol. Goiano Geogr. Goiânia: v. 31, n. 2, p. 29-42, jul./dez., 2011.

GALVÃO, E. U. P; MENEZES, A. J. E. A; VILAR, R. R. L; SANTOS, A. A. R. Análise da renda e da mão de obra nas unidades agrícolas familiares da comunidade de Nova Colônia, município de Capitão Poço, Pará. Amazônia: Ci. \& Desenv., Belém, v.1, n.1, jul. /dez. 2005.

GONÇALVES, M. M. D. C. F., MELO, A. D. S.,; VITAL, T. W. (2014). Estudo de casos de agroindústria da agricultura familiar em Pernambuco. Universidade Federal Rural de Pernambuco.

GUANZIROLI, C. et al. Agricultura familiar e reforma agrária no século XXI. Rio de Janeiro: Garamond, 2001.

LASSAK, S. (2010). Lutando por terra e vida! (Portuguese).: fighting for land and life. (english). Teocomunicação, 40 (2) 238-280.

MAIA, A. H., SANT'ANA, A. L. (2011). Vivências e projetos das jovens rurais: um olhar sob a sua condição de mulher na agricultura familiar e a relação com suas estratégias de vida. (Dissertação de Mestrado, Universidade Estadual Paulista (UNESP), Ilha Solteira). COSTA, C. et al. Masculinização rural por faixa etária: apontamentos para o RS. Rev Congrega URCAMP, Bagé, v.3, p.1-13, 2009.

MARION, Aline Adriana; BONA, Aldo Nelson. A IMPORTÂNCIA DA MULHER NA AGRICULTURA FAMILIAR. Revista Cafeicultura, Minas Gerais, v. 13, p.1-11, set. 2013.

MATOS, G. R.; MARIN, O. B. Agricultores familiares e sistemas de produção de frutas em Itapuranga, Goiás. ISSN 1517-6398/ e-ISSN 1983-4063 www.agro.ufg.br/pat - Pesq. Agropec. Trop., Goiânia, v. 39, n. 3, p. 197-206, jul./set. 2009

MESQUITA, Lívia Aparecida Pires de. O papel das mulheres na agricultura familiar: a comunidade Rancharia, Campo Alegre de Goiás. 2013. 137 f. Dissertação (Mestrado) - Curso de Pós Graduação Stricto Sensu em Geografia, Universidade Federal de Goiás, Catalão (GO), 2013.

MESQUITA, Lívia Aparecida Pires de; MENDES, Estevane de Paula Pontes. AGRICULTURA FAMILIAR, TRABALHO E ESTRATÉGIAS: a participação feminina na reprodução socioeconômica e cultural. Espaço em Revista, Goiás, v. 14, n. 1, p.14-23, jun. 2012.

NOGUEIRA, Rita de Cássia Maciazeki Gomes e Conceição et al. MULHERES EM CONTEXTOS RURAIS: UM MAPEAMENTO SOBRE GÊNERO E RURALIDADE. Psicologia e Sociedade, Belo Horizonte, v. 28, n. 1, p.1-10, abr. 2016. OLIVEIRA, Ariovaldo Umbelino de. Modo de Produção Capitalista, Agricultura e Reforma Agrária. São Paulo: Labur Edições, 2007, 184p. 
PILAR, J. A., ERNST, A. (2013). Ser mulher: O sujeito do desejo na fronteira entre o sagrado e o profano. (Tese de Doutorado, Universidade Católica de Pelotas, Pelotas). PINTO, N. M. A., PONTES, F. A. R. \& SILVA, S. S. C. (2013). A rede de apoio social e o papel da mulher na geração de ocupação e renda no meio rural. Temas psicol. 21 (2), 297-315. doi: 10.9788/TP2013.2-01.

RÖHNELT, PRISCILA BARCELOS CARDOSO E SALAMONI, GIANCARLA. O papel da mulher nas transformações da agricultura familiar: a pluriatividade como estratégia de reprodução social. Universidade Federal do Rio Grande (FURG), 2010, p.01-115.

SALVARO, G. I. J., LAGO, M. C. S.; WOLFF, C. S. (2013). "Mulheres agricultoras" e "mulheres camponesas": lutas de gênero, identidades políticas e subjetividades. Psicol. Soc., 25 (1), 79-89. doi: 10.1590/S0102-71822013000100010.

SCHNEIDER, Sérgio. Teoria social, agricultura familiar e pluriatividade. Rev. bras. Ci. Soc., São Paulo, v. 18, n. 51, fev. 2003.

SOUZA, Katiane de; PLEIN, Clério. A PARTICIPAÇÃO DAS MULHERES NO COOPERATIVISMO DE CRÉDITO SOLIDÁRIO: O CASO DA CRESOL NO SUDOESTE DO PARANÁ. In: MENDONÇA, Paulo Rogério de. Saberes da cooperação. Francisco Beltrão - Pr: Grafisul Gráfica e Editora Ltda, 2015. p. 293-321.

TEDESCO, J. C. Terra, trabalho e família: racionalidade produtiva e ethos camponês. Passo Fundo: EDIUPF, 1999. 331p. 